\title{
Dobraduras Dinâmicas e a Argumentação em Geometria
}

\author{
Priscila Ferreira Silveira - PPGEMAT/UFRGS - pry.f.silveira@ gmail.com \\ Márcia Rodrigues Notare - PPGEMAT/UFRGS - marcia.notare@ufrgs.br
}

\section{Resumo}

Nesse artigo analisa-se o desenvolvimento do pensamento geométrico e da argumentação a partir da exploração de situações geométricas de dobraduras em ambiente de geometria dinâmica. A investigação foi conduzida por um experimento, com alunos do nono ano do Ensino Fundamental. Por meio de investigação geométrica, foram elaboradas atividades dinâmicas, nas quais se oportunizou o desenvolvimento de aspectos essenciais do pensamento geométrico, como a exploração, formulação e teste de conjecturas, assim como o incentivo à argumentação na escola. Essa investigação foi realizada com o software GeoGebra, a partir da manipulação de objetos geométricos dinâmicos que simulam dobraduras em folhas de papel, nos quais os alunos foram incentivados a explorar e argumentar. Os resultados do experimento apontam que, com a utilização de ambiente de geometria dinâmica, é possível resgatar o trabalho com o desenvolvimento do pensamento geométrico na escola básica.

Palavras-chave: geometria dinâmica, tecnologias digitais, educação matemática, pensamento geométrico, argumentação em geometria

\section{Dynamic Folding Argumentation in Geometry}

\begin{abstract}
In this article, the development of geometric thinking and argumentation is analyzed based on the exploration of geometric folding situations in a dynamic geometry environment. The investigation was conducted by an experiment, with students in the ninth grade of elementary school. Through geometric investigation, dynamic activities were developed, in which the development of essential aspects of geometric thought, such as exploration, formulation and conjecture testing, as well as the encouragement of argument at school, was provided. This investigation was realized with the GeoGebra software, from the manipulation of dynamic geometric objects that simulate folds on sheets of paper, in which the students were encouraged to explore and argue. The results of the experiment show that, with the use of a dynamic geometry environment, it is possible to rescue work with the development of geometric thinking in the basic school.
\end{abstract}

Keywords: dynamic geometry, digital technologies, mathematical education, geometric thinking, argument in geometry

\section{Introdução}

A Geometria consiste na área da Matemática caracterizada pelo estudo de propriedades de figuras geométricas no plano ou no espaço. Tais propriedades se desenvolvem em um sistema axiomático-dedutivo, característico desse campo da Matemática. Nesse contexto, o processo de argumentação torna-se uma habilidade essencial para o desenvolvimento do pensamento geométrico. Para Notare e Basso (2018) ações como experimentar, formular conjecturas, testá-las e validá-las são processos naturais que constituem o pensamento geométrico.

Gravina e Contiero (2011) apontam sobre a importância do desenvolvimento do pensamento geométrico pelos estudantes. Entretanto, para esses autores, ações como estabelecer relações, abstrair propriedades, generalizar e argumentar costumam ser V. $18 \mathrm{~N}^{\mathrm{o}} 1$, julho, 2020 RENOTE DOI: 
estranhas aos alunos. Portanto, torna-se importante proporcionar situações para o estudo da Geometria que provoquem essas ações e desencadeiem o desenvolvimento do pensamento geométrico, de forma que sejam analisadas e exploradas propriedades e sejam construídos conceitos, evitando procedimentos mecânicos e memorização de fórmulas.

Para Stahl (2013), o desenvolvimento de ambientes de geometria dinâmica oferece uma oportunidade para transformar o estudo da geometria, muitas vezes ossificado e rígido, em uma versão contemporânea, mas que preserva sua essência axiomática-dedutiva e as ações essenciais que possibilitam seu desenvolvimento.

Nesse contexto, Armella (2016) defende duas habilidades como essenciais para os alunos: construir e explorar modelos dinâmicos para examinar um grande número de exemplos; identificar e formular conjecturas ou invariâncias e procurar argumentos para apoiar as relações matemáticas. Dessa forma, as tecnologias digitais possibilitam representações dinâmicas que podem desenvolver a habilidade de argumentação. Para esse autor, levar o aluno pelo caminho de argumentos visuais pode contribuir para o caminho de provas mais formais, a partir do estabelecimento de relações entre raciocínio empírico e raciocínio dedutivo.

Nesse artigo, recorte de uma pesquisa de mestrado acadêmico em Ensino de Matemática da Universidade Federal do Rio Grande do Sul (PPGEMAT/UFRGS), apresentamos um estudo sobre desenvolvimento do pensamento geométrico com estudantes de nono ano do Ensino Fundamental, em ambiente de geometria dinâmica. Analisamos como a exploração de dobraduras virtuais no GeoGebra proporcionou o desenvolvimento de habilidades próprias do pensamento geométrico, como identificar relações, fazer conjecturas, testar e argumentar.

Destacamos que não tínhamos como objetivo a realização de demonstrações formais, mas sim o desenvolvimento do pensamento geométrico, a comunicação, na linguagem dos estudantes, do entendimento das propriedades e da validação de suas conjecturas, encorajando-os nesse universo argumentativo e resgatando a essência do pensamento geométrico em tempos modernos.

Dessa forma, como ocorre a aprendizagem de propriedades geométricas que emergem da exploração de dobraduras em ambiente de geometria dinâmica é a questão norteadora dessa pesquisa. Para conduzir a investigação, foi desenvolvido um GeoGebraBook, ou seja, um material dinâmico on-line e interativo desenvolvido com o GeoGebra, com uma sequência de atividades dinâmicas de exploração de dobraduras virtuais (https://www.geogebra.org/m/kg5tgaed).

$\mathrm{Na}$ sequência do artigo, apresentamos a fundamentação teórica do trabalho, as escolhas metodológicas e a análise de duas atividades, recorte de uma sequência mais ampla, elaborada para analisar o processo de argumentação de estudantes.

\section{Geometria dinâmica e o pensamento geométrico}

A Geometria Euclidiana trata do saber matemático referente a objetos idealizados, ou seja, objetos que não existem no mundo físico, apenas no mundo das ideias. Segundo Gravina (2001), esses objetos originam-se de processos de abstração e generalização, e no processo de aprendizagem da Geometria, as idealizações sofisticam-se e os registros perceptivos transformam-se em objetos geométricos pela conceituação de suas propriedades e características. Com isso, o aluno que identifica uma figura geométrica inicialmente apenas pela sua aparência física e, posteriormente, determina a figura geométrica pelas suas propriedades, está avançando no processo de aprendizagem de Geometria. Esse processo de identificação de propriedades, que se inicia pela exploração, testes e realização de conjecturas, desencadeia a fase de validação e argumentação. 
De Villiers (1997) comenta que a motivação para uma argumentação de determinada propriedade geométrica é a convicção da mesma, ou seja, temos que estar convencidos de que ela é verdadeira para querer prová-la. Assim, o desenvolvimento de uma argumentação é realizado após tomar-se uma propriedade como verdadeira. $\mathrm{O}$ autor também argumenta que a falta de argumentação de uma propriedade reflete na falta de compreensão sobre a mesma. Ou seja, argumentar e deduzir seriam formas de entendimento, algo mais do que apenas saber que a propriedade é verdadeira, de convencer seu raciocínio da veracidade.

Segundo Notare e Basso (2018),

Atualmente, ambientes de geometria dinâmica têm colaborado para o resgate das discussões sobre a importância da prova nas aulas de Matemática. A possibilidade de movimentar figuras construídas com propriedades geométricas que as definem faz realçar regularidades e propriedades importantes no processo de argumentação, que se mantêm estáveis durante o movimento e proporcionam um espaço para a elaboração, teste e validação de conjecturas, etapas importantes do processo dedutivo. Mais do que isso, atividades nesses ambientes provocam nos estudantes a necessidade de provar para comprovar o que está sendo observado e abstraído do processo de experimentação e descoberta. (Notare e Basso, 2018, p.2)

Uma das características principais da geometria dinâmica é a possibilidade de arrastar na tela objetos geométricos construídos, o que possibilita ações de exploração e identificação de regularidades, que ficam estáveis quando movimentadas. Destacamos, entre outras, duas categorias para a ação de arrastar: arrastar para explorar e conjecturar e arrastar para validar uma conjectura ou prova (Basso e Notare, 2015). Na primeira categoria, os alunos arrastam objetos geométricos para observar a figura em busca de regularidades e invariantes. Na segunda categoria, os alunos arrastam um objeto geométrico para verificar uma conjectura já descoberta. A ação de arrastar, característica essencial da geometria dinâmica, está presente nessa pesquisa, no processo de exploração da dobradura virtual, ou seja, a ação de arrastar e manipular a dobradura dará aos estudantes suporte para explorar e conjecturar.

Retomando a discussão sobre a importância do processo de argumentação na escola, para De Villiers (1997), a principal função didática da prova matemática não é a de verificação, mas sim de explicação. $O$ autor argumenta que essas provas, de explicação, produzem conhecimento sobre os conceitos relevantes e são mais importantes do que apenas confirmar um resultado. Ou seja, a aprendizagem ocorre quando o indivíduo é capaz de realizar argumentações para explicar uma ideia ou conceito. $\mathrm{O}$ autor afirma que, para o desenvolvimento da argumentação, devem ser permitidos ao aluno a oportunidade de explorações, conjecturas, testes, refutações, reformulações e explicações. Para o autor, ambientes de geometria dinâmica incentivam esses processos de pensamento.

Essas atividades matemáticas que estabelecem um movimento de idas e vindas envolvem explorações informais, falsos começos, formulação de conjecturas e explicações parciais antes de construir argumentos formais ou provas (Armella, 2016).

Em relação aos ambientes de geometria dinâmica, Basso e Notare (2015) citam que uma das principais contribuições desses ambientes é a evolução do conceito de prova em Geometria. Nesses ambientes, podem ser oferecidas atividades que favoreçam a exploração, a conjectura, a argumentação, a discussão e, por fim, a prova. Assim, a noção de prova em Matemática escolar muda com a experimentação, pois torna-se um processo de procurar argumentos que explicam a veracidade de uma afirmação, de acordo com regras de consequência lógica. E é nesse sentido que entendemos a argumentação em nossa pesquisa. 


\section{Dobraduras no ensino de Geometria}

Menezes (2014) comenta que as dobraduras em origami foram objetos de estudos em meados da década de 70. Humiaki Huzita foi um matemático que nasceu no Japão, porém viveu a maior parte da vida na Itália. Huzita ficou conhecido por formular os primeiros axiomas, chamados inicialmente de operações básicas, que descreviam a matemática de dobrar o papel com o intuito de resolver problemas de construção geométrica. Apresentamos a seguir os axiomas das dobras de papel propostos por Huzita, ilustrados por dobraduras propostas nessa pesquisa.

O Axioma 1 diz que, dados dois pontos, $P_{1}$ e $P_{2}$, há uma única dobra que passa pelos dois pontos (Figura 1). Nessa situação, podemos dizer que essa dobra é uma reta que contém tais pontos, remetendo ao primeiro postulado de Euclides, que afirma que existe uma única reta que passa por dois pontos distintos.

Figura 1 - Exemplo de Axioma 1

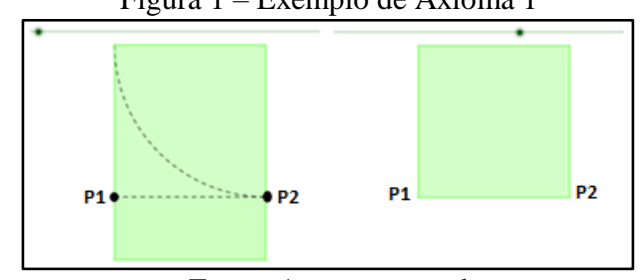

Fonte: Acervo pessoal

O Axioma 2 diz que, dados dois pontos, $P_{1}$ e $P_{2}$, há uma única dobradura que os torna coincidentes (Figura 2). Nessa dobradura, é construída a mediatriz do segmento $\overline{P_{1} P_{2}}$, podendo ser encontrado também o ponto médio do segmento $\overline{P_{1} P_{2}}$ pela intersecção do segmento $\overline{P_{1} P_{2}}$ com a mediatriz. Pin e Uribe (2016) associam esse Axioma à existência e unicidade da mediatriz do segmento $\overline{P_{1} P_{2}}$.

Figura 2 - Exemplo do Axioma 2

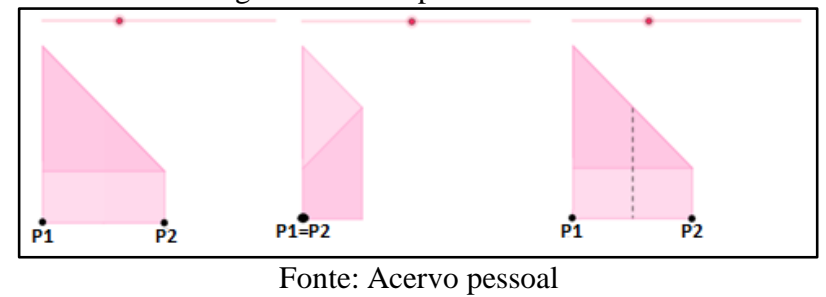

O Axioma 3 diz que, dadas duas retas $r_{1}$ e $r_{2}$, existe apenas uma dobra que faz coincidir $r_{1}$ com $r_{2}$ (Figura 3). Nessa dobradura, se as retas $r_{1}$ e $r_{2}$ forem paralelas, então a dobra descreverá uma reta paralela às retas $r_{1}$ e $r_{2}$. Se as retas $r_{1}$ e $r_{2}$ forem concorrentes, a dobra descreve a bissetriz dos ângulos entre as retas, sendo que há duas possibilidades de dobrar e não apenas uma. Pin e Uribe (2016) associam esse axioma às bissetrizes dos ângulos formados pela intersecção das duas retas. Podemos observar esse axioma na Dobradura 3 das atividades propostas nessa pesquisa, em que o lado esquerdo e o lado direito da folha de papel A4, ao coincidirem, formam uma dobra paralela a esses dois lados, como mostra a Figura 2.

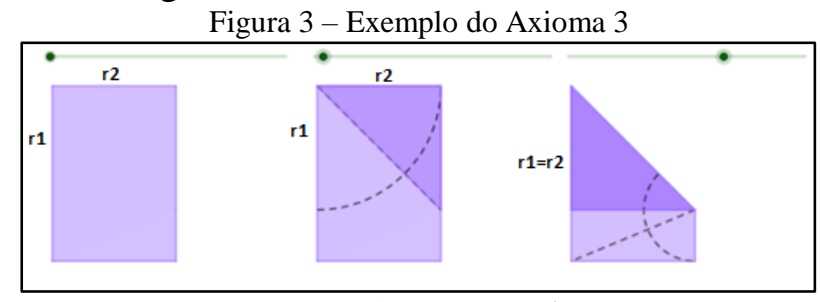

Fonte: Acervo pessoal

O Axioma 4 diz que, dados um ponto $\mathrm{P}$ e uma reta $\mathrm{r}$, existe uma única dobra que é perpendicular à reta $\mathrm{r}$ que passa por $\mathrm{P}$ (Figura 4). Pin e Uribe (2016) associam esse axioma à existência e unicidade da reta perpendicular que passa por um ponto. 
Figura 4 - Exemplo do Axioma 4

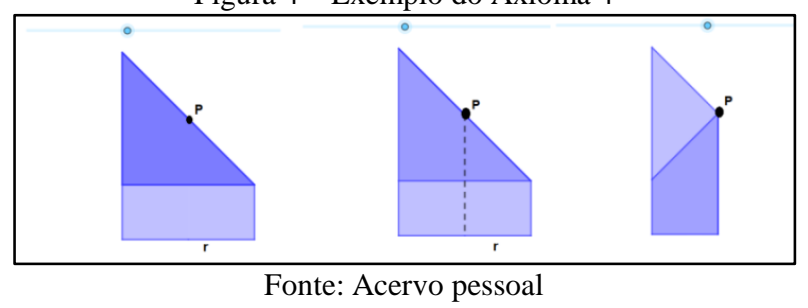

O Axioma 5 diz que, dados dois pontos distintos $P_{1}$ e $P_{2}$ e uma reta $\mathrm{r}$, existe uma dobra que faz incidir $P_{1}$ em r e que passa por $P_{2}$ (Figura 5). Pin e Uribe (2016) afirmam que a quantidade de soluções desse axioma pode ser nenhuma, uma ou duas, dependendo da posição dos pontos e da reta, pois é equivalente a encontrar a intersecção da reta $\mathrm{r}$ com um círculo com centro em $P_{2}$ e de raio $\bar{P}_{1} P_{2}$.

Figura 5 - Exemplo do Axioma 5

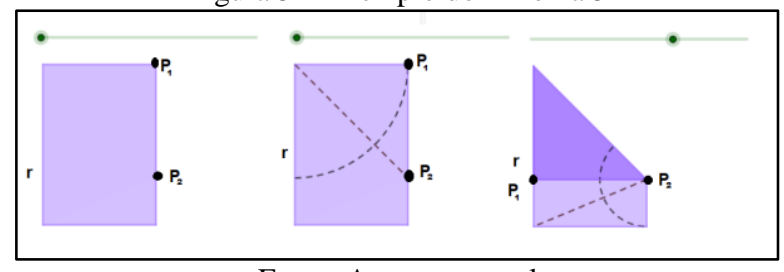

Fonte: Acervo pessoal

O Axioma 6 diz que, dados dois pontos distintos $P_{1}$ e $P_{2}$ e duas retas distintas $\mathrm{r}$ e s, existe uma dobra que faz incidir $P_{1}$ sobre r e $P_{2}$ sobre s. Pin e Uribe (2016) afirmam que esse axioma não pode ser construído com régua e compasso. Esse axioma não foi identificado nas dobraduras dessa pesquisa.

O Axioma 7 diz que, dados um ponto $\mathrm{P}$ e duas retas $\mathrm{r}$ e s, existe uma dobra que faz coincidir $\mathrm{P}$ em $\mathrm{r}$ e é perpendicular à reta $\mathrm{s}$ (Figura 6$)$.

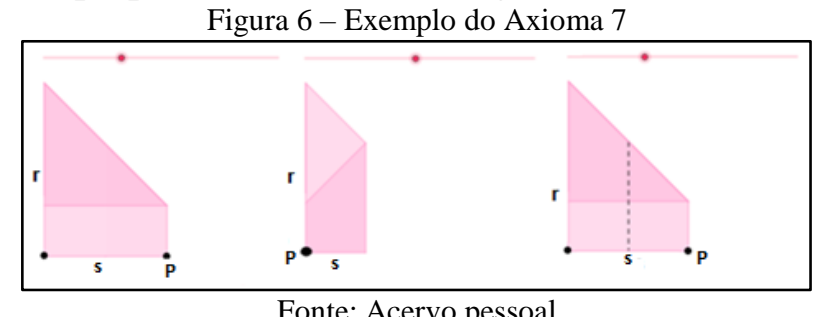

Fonte: Acervo pessoal

Apresentamos esses axiomas no artigo, pois os mesmos dão suporte, mesmo que de forma implícita, aos argumentos que justificam as propriedades geométricas das dobraduras utilizadas nessa pesquisa, assim como os pensamentos dos estudantes. $\mathrm{Na}$ seção a seguir, apresentados os procedimentos metodológicos.

\section{Procedimentos e métodos}

A pesquisa aqui apresentada tem cunho qualitativo, na qual buscamos compreender como se dá a aprendizagem de propriedades geométricas e o desencadeamento de argumentações que emergem da exploração de dobraduras em ambiente de geometria dinâmica. Nessa perspectiva, as respostas não são objetivas e o propósito não é contabilizar quantidades como resultados, mas sim conseguir compreender o comportamento dos estudantes no ambiente de geometria dinâmica, diante das atividades propostas. Estamos interessados em investigar o processo de descoberta e desenvolvimento do pensamento geométrico dos estudantes, e não o resultado ou produto final de suas participações. Realizamos um estudo do processo e das produções dos estudantes, buscando identificar indícios de desenvolvimento de pensamento geométrico, a partir da observação de propriedades referenciadas, utilizadas ou descobertas ao longo do trabalho com dobraduras virtuais. 
Bogdan e Biklen (1994) afirmam que a pesquisa qualitativa possui cinco características, porém nem todos os estudos considerados qualitativos apresentam todas estas características. A primeira característica é que "Na investigação qualitativa a fonte direta de dados é o ambiente natural, constituindo o investigador o instrumento principal." (Bogdan e Biklen, 1994, p.47), ou seja, na pesquisa qualitativa o investigador se introduz no ambiente da pesquisa e coleta dados (diário de campo, registros dos alunos, etc.) e, ao analisar os dados coletados e produzidos, pode revê-los na sua totalidade, pois o investigador possui observações do contexto da produção desses dados. A segunda característica da pesquisa qualitativa é a descrição, os dados recolhidos são em forma de palavras ou imagens e não de números. O que caracteriza a pesquisa qualitativa é que os investigadores tentam analisar os dados em toda a sua riqueza, nenhum dado é simplificado. A terceira característica da pesquisa qualitativa é que os investigadores se interessam mais pelo processo do que pelo resultado ou produto. A quarta característica é que "Os investigadores qualitativos tendem a analisar os seus dados de forma indutiva. "(Bogdan e Biklen, 1994, p.50), ou seja, os investigadores não recolhem dados para provar ou não hipóteses construídas previamente, mas sim, constroem abstrações conforme os dados recolhidos vão agrupando-se. Finalmente, a quinta característica é que "O significado é de importância vital na abordagem qualitativa." (Bogdan e Biklen, 1994, p.50), ou seja, a perspectiva do indivíduo, como ele entende sobre certo problema.

Para a realização da pesquisa, parte de uma dissertação de mestrado, foi oferecida uma oficina para as turmas de nono ano de uma escola da rede estadual de Ensino Fundamental. A oficina foi organizada em cinco encontros, com duração de duas horas cada encontro. Para produção dos dados, foram utilizados os seguintes instrumentos: diário de campo em todos os encontros, com anotações da professora-pesquisadora; registros escritos dos estudantes em editor de texto, a fim de produzir dados que forneçam indícios de seus pensamentos durante a realização das atividades; gravação de vídeos, a fim de investigar o processo de cada aluno a partir de suas colocações e de intervenções que busquem elucidar dados importantes. Participaram da oficina treze estudantes.

A oficina foi organizada em um livro digital no GeoGebrabook com as dobraduras e sequências de atividades (https://www.geogebra.org/m/kg5tgaed). Ao acessar o material, é possível visualizar um resumo do livro e seus capítulos, dividido em cinco dobraduras organizadas em atividades que denominamos Investigações e a atividade final, denominada Agora é a sua vez!, como ilustra a Figura 7. A estrutura geral das investigações foi pensada para contemplar etapas do pensamento geométrico como: 1) manipular e explorar; 2) realizar conjecturas, identificando características e propriedades gerais das figuras; 3) realizar conjecturas, identificando propriedades geométricas que definem as figuras; e 4) argumentar sobre as conjecturas realizadas.

Figura 7- Tela Inicial do Livro Digital

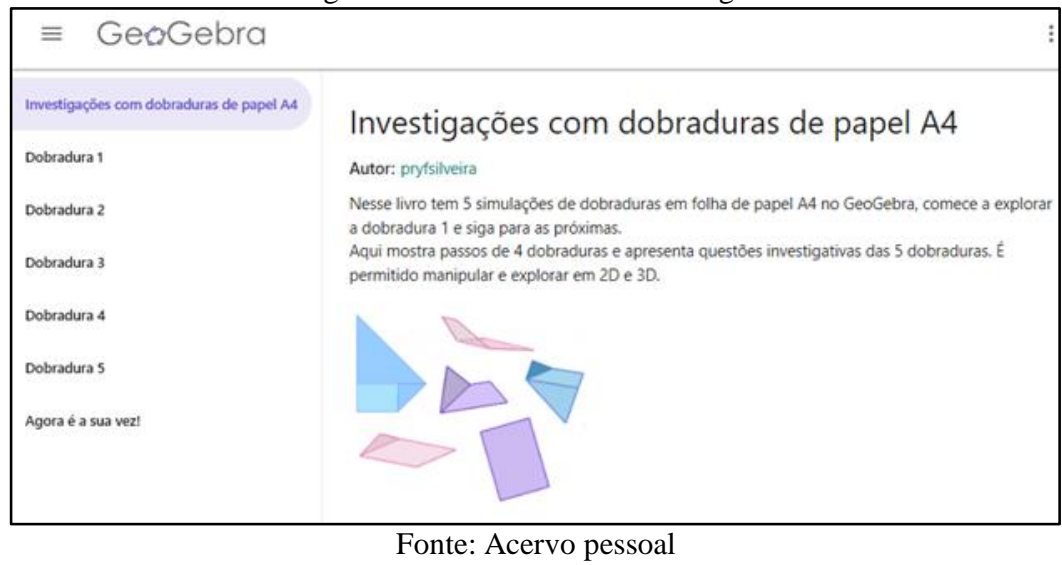

A seguir, apresentamos a análise de duas atividades de dobraduras.

V. $18 \mathrm{~N}^{\mathrm{o}} 1$, julho, 2020

DOI: 


\section{Análise - A argumentação dos alunos da escola básica}

Nessa seção, apresentamos e analisamos duas atividades de dobradura, para evidenciar o processo de exploração e argumentação no ambiente dinâmico proposto pela pesquisa. Os estudantes, a partir da manipulação de um controle deslizante no GeoGebra, puderam explorar no livro digital as dobraduras virtuais de folhas de papel que formavam figuras geométricas com determinadas propriedades. A partir da identificação dessas propriedades, os estudantes eram convidados a justificar a validade das mesmas.

A primeira dobradura que vamos analisar é Dobradura 3 do livro digital, que forma um paralelogramo. A tela inicial dessa atividade está ilustrada na Figura 8 , na qual é possível explorar dinamicamente o processo de dobradura na folha. A Figura 9 apresenta uma sequência de imagens para ilustrar o dinamismo da dobradura, até formar o paralelogramo.

Figura 8 - Tela da Dobradura 3

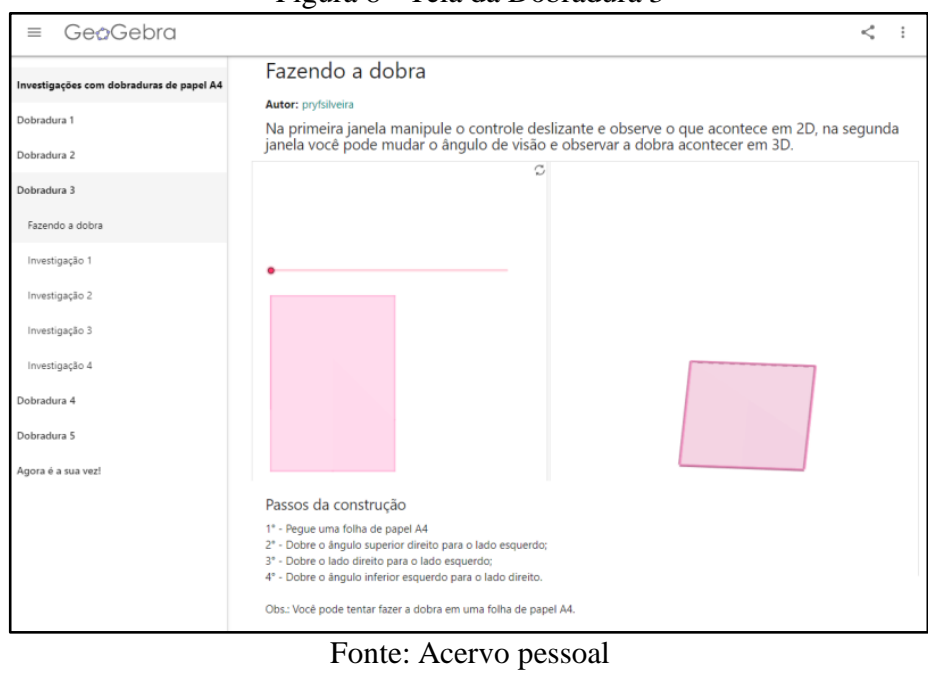

Figura 9 - Passos da Dobradura 3

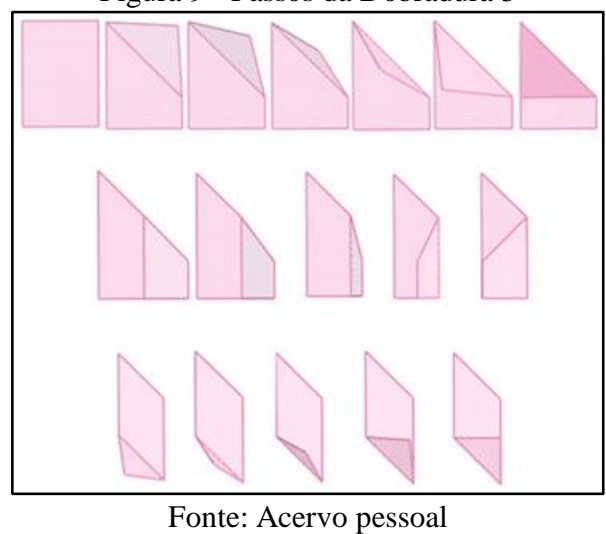

A partir de questionamentos que tinham o propósito de provocar a exploração da dobradura dinâmica para a realização das primeiras conjecturas, os estudantes foram desafiados a observar os lados da figura que se formava (O que podemos dizer sobre os lados dessa figura? Por quê?). Um grupo de alunos respondeu que "Os lados opostos são paralelos e iguais".

Analisando a resposta, percebemos que os alunos identificaram que os lados opostos de um paralelogramo precisam ter mesma medida. Para avançar no processo de exploração e argumentação, nesse momento, foi solicitado aos alunos que argumentassem que a figura é, de fato, um paralelogramo, ou seja, que utilizassem argumentos sustentados por propriedades geométricas decorrentes das dobraduras realizadas. Os estudantes não tinham experiências prévias com demonstrações e um dos alunos sugeriu 
apoiar os argumentos nos ângulos observados. A partir dessa observação, a pesquisadora comentou que duas retas são paralelas se a reta perpendicular a uma delas é também perpendicular à outra, para observar se a informação poderia dar suporte à argumentação. Os alunos manipularam novamente a dobradura e discutiram sobre como argumentar sobre as propriedades dos lados do paralelogramo. Os extratos a seguir apresentam uma sequência de reflexões dos alunos, que levaram à justificativa do paralelismo dos lados.

- Como aqui tem $180^{\circ}$ e a linha está partindo no meio, tem $90^{\circ}$ de cada lado (noção de bissetriz)

- Então a gente pegou o $90^{\circ}$ e dobrou no meio e ficou $45^{\circ}$ (noção de bissetriz novamente)

- Então tem o $45^{\circ}$ e aqui ficou $90^{\circ}$

- Como nós temos uma folha que é quadrada nas pontas, nós temos $90^{\circ}$ aqui (noção de perpendicularidade)

- E como nós dobramos os $90^{\circ}$ aqui e aqui tem $180^{\circ}$ (noção de ângulo raso)

- Aqui então tem $90^{\circ}$ porque $90+90=180$ (noção de ângulos suplementares)

- Então esses lados são paralelos, o lado direito e o lado esquerdo (propriedade de retas paralelas e perpendiculares)

Para compreender e analisar o processo de argumentação dos alunos, vamos observar a Figura 10. Na argumentação, o que chamaremos de Aluno 1, com o auxílio de seus colegas, argumenta que os lados direito $(\overline{D E})$ e esquerdo $(\overline{A F})$ da figura são paralelos. Analisando a argumentação do grupo, identificamos que, primeiro o Aluno 1 observa que o segmento $\overline{A B}$, que representa a marca da dobradura, é a bissetriz do ângulo $C \hat{A} F$, que mede $180^{\circ}$ (o Axioma 3 de Huzita sustenta essa afirmação). Com isso, o Aluno 1 deduz que os ângulos $C \hat{A} B$ e $B \hat{A} F$ medem $90^{\circ}$, concluindo a perpendicularidade entre os segmentos $\overline{A B}$ e $\overline{C F}$. Em seguida, o Aluno 1 identificou o segmento $\overline{A D}$ como a bissetriz do ângulo $C \hat{A} B$, concluindo que o ângulo $D \hat{A} B$ mede $45^{\circ}$ (novamente, o Axioma 3 sustenta a afirmação). Em seguida o Aluno 1 argumenta que, ao fazer coincidir o ponto $\mathrm{C}$ com o ponto $\mathrm{B}$, os ângulos $D \hat{C} A$ e $D \hat{B} A$ também coincidem. Como o ângulo $D \hat{C} A$ é um dos ângulos da folha de papel, o Aluno 1 concluí que o ângulo $D \widehat{B} A$ mede $90^{\circ} \mathrm{e}$ argumenta que, como o ângulo $D \hat{B} E$ mede $180^{\circ}$, então o ângulo $A \hat{B} E$ mede $90^{\circ}$, implicitamente utilizando a ideia de ângulos suplementares. Finalmente, o Aluno 1 conclui paralelismo entre os segmento $\overline{A F}$ e $\overline{D E}$. Nessa argumentação, evidencia-se que os alunos construíram ou utilizaram uma série de conceitos matemáticos, como perpendicularidade, paralelismo, bissetriz, ângulos suplementares, e organizaram uma sequência lógica de argumentos, característica do pensamento geométrico. Assim como De Villiers (1997) afirma, a aprendizagem ocorre quando o aluno usa de argumentações para explicar um conceito. Evidentemente, não temos uma argumentação formal, mas uma sequência de argumentos que explicam a veracidade de suas observações, conforme defendem Basso e Notare (2015).

Figura 10 - Dobradura 3

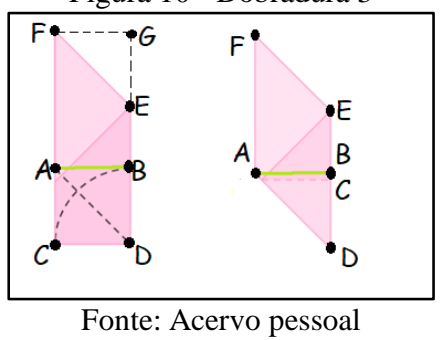

Outra situação que analisaremos nesse artigo refere-se à Dobradura 4 do livro digital, que forma um trapézio (Figura 11). Trazemos aqui a discussão sobre os ângulos do trapézio formado pela dobradura virtual ( $\mathrm{O}$ que podemos dizer sobre os ângulos da figura construída? Por quê? e Que medidas tem esses ângulos? Por quê?). A resposta dos alunos para essas questões foi: "Dois obtusos e dois agudos. Dois ângulos de 45 graus e dois de 135 graus".

DOI: 
Figura 11- Dobradura 4

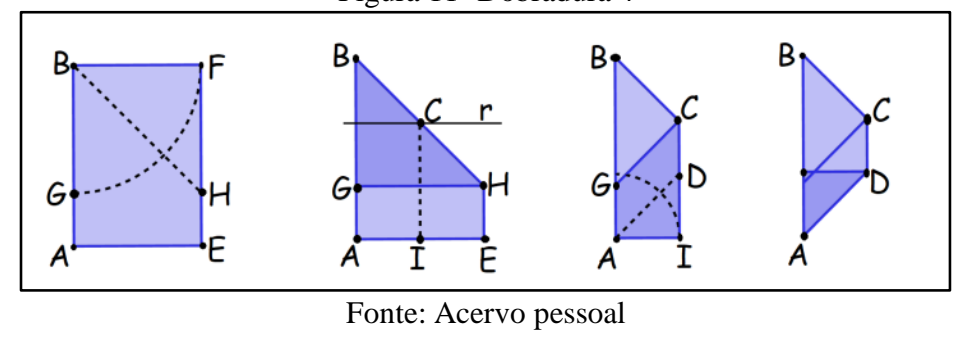

Manipulando a dobradura virtual e observando o comportamento dos ângulos, os alunos identificaram que os segmentos $\overline{A D}$ e $\overline{B C}$ são respectivamente as bissetrizes dos ângulos $E \hat{A} B$ e $A \hat{B} F$ (Axioma 3). Portanto, os alunos concluíram que os ângulos $D \hat{A} B$ e $A \hat{B} C$ medem $45^{\circ}$, e os denominaram de ângulos agudos.

Os alunos perceberam, a partir da exploração da dobradura no GeoGebra, possibilitada pela ação de arrastar do controle deslizante, que, ao dobrar o ponto $\mathrm{F}$ sobre o segmento $\overline{A B}$, obtém-se o ângulo $D \hat{C} B$ medindo $135^{\circ}$. Pois, seja r uma reta paralela ao segmento $\overline{A E}$ que passa pelo ponto $\mathrm{C}$, o segmento $\overline{I C}$ é perpendicular à reta $\mathrm{r}$, com isso, o segmento $\overline{B H}$ é a bissetriz do ângulo $\hat{C}$, então o ângulo $I \hat{C} H$ mede $45^{\circ}$. Os estudantes identificaram o ângulo raso $H \hat{C} B=180^{\circ}$, e então determinaram o ângulo $I \hat{C} B=H \hat{C} B-$ $I C H=135^{\circ}$. Em seguida, ao dobrar o ponto I sobre o segmento $\overline{A B}$, os estudantes argumentaram que está sendo subtraído $45^{\circ}$ do ângulo raso $I \widehat{D} C$, pois perceberam que o segmento $\overline{A D}$ é bissetriz do ângulo $I \widehat{D} G$, que identificaram medir $90^{\circ}$. Sendo assim, $A \widehat{D} C=I \widehat{D} C-I \widehat{D} A=135^{\circ}$. Com isso, os estudantes identificaram os ângulos $A \widehat{D} C \mathrm{e}$ $D \hat{C} B$ como obtusos.

Assim como na análise da Dobradura 3, nessa dobradura os alunos utilizaram uma série de conceitos matemáticos, como perpendicularidade, paralelismo, bissetrizes, classificações de ângulos, e organizaram uma sequência lógica de argumentos, para explicar suas conjecturas, elaboradas a partir das explorações no modelo dinâmico. Mesmo que os alunos não tenham apresentado uma argumentação formal, clássica da Geometria Euclidiana, há evidências de argumentações que explicam a veracidade de suas observações, corroborando com De Villiers (1997), Armella (2016) e Basso e Notare (2015), que defendem que o processo de prova na educação básica pode ser desassociado do rigor matemático. Percebemos nas análises dos dados que os alunos avançaram no processo de aprendizagem de Geometria, pois conforme Gravina (2001), esse processo ocorre quando o aluno passa de um estágio de apenas identificar uma figura geométrica pela sua aparência física, para determinar a figura geométrica pelas suas propriedades. Atividades que provocam o exercício da argumentação e justificativa favorecem esse processo e realçamos com os dados dessa investigação que isso é possível.

Observamos que os alunos, desafiados pelas atividades virtuais de dobradura, foram convidados a vivenciar ações importantes para o desenvolvimento do pensamento geométrico, como explorar, manipular, conjecturar, testar e argumentar. Os argumentos apresentados pelos estudantes não consistem em provas rigorosas de Geometria, mas revelam um processo importante de desenvolvimento do pensamento geométrico e nos encorajam no trabalho de resgate de atividades de argumentação na sala de aula de Matemática da escola básica.

\section{Considerações finais}

O resgaste e incentivo à argumentação nas aulas de Matemática da educação básica é o pilar dessa pesquisa. Os ambientes de geometria dinâmica trouxeram à tona a discussão sobre as possibilidades do trabalho em sala de aula com a essência da Geometria Euclidiana, ou seja, o resgate do desenvolvimento de habilidades matemáticas 
de exploração, testes, conjecturas e argumentações. A partir de atividades de manipulação de dobraduras virtuais no GeoGebra, convidamos os alunos a identificarem regularidades e propriedades de figuras geométricas que se formavam e, em seguida, argumentarem sobre suas constatações. Identificamos que, desafiar os estudantes a argumentar sobre as conjecturas que elaboram, proporciona um trabalho inicial com o desenvolvimento de provas. Evidentemente, os argumentos apresentados pelos alunos são para comunicar e expressar seus entendimentos sobre propriedades (e não caracterizam demonstrações matemáticas formais), mas evidenciam que é possível esse trabalho em sala de aula, com uma versão contemporânea possibilitada pela geometria dinâmica.

\section{Referências}

ARMELLA, Luis Moreno; TRIGO, Manuel Santos; MACHIN, Matías Camacho. Problem solving and the use of digital Technologies within the Mathematical Working space framework. ZDM Mathematics Education, 48, p. 827-842, fev, 2016.

BASSO, Marcus; NOTARE, Márcia. Pensar com Tecnologias Digitais de Matemática Dinâmica. Revista Novas Tecnologias na Educação, v. 13, n. 2, dez, 2015.

BOGDAN, Robert; BIKLEN, Sari. Investigação qualitativa em educação: uma introdução à teoria e aos métodos. Portugal: Porto Editora, 1994.

DE VILLIERS, M. The Role of Proof in Investigative, computer-based Geometry: Some personal reflections. Chapter in Schattschneider, D. \& King, J. (1997). Geometry Turned On! Washington: MAA, p. 15-24.

GRAVINA, Maria Alice. Os ambientes de geometria dinâmica e o pensamento hipotético-dedutivo. Porto Alegre: UFRGS, 2001. 277 p. Tese de doutorado, curso de Pós-Graduação em informática na Educação, Universidade Federal do Rio Grande do Sul, 2001. Disponível em <http://hdl.handle.net/10183/2545> . Acesso em: 16/03/2019.

GRAVINA, Maria; CONTIERO, Lucas. Modelagem com o GeoGebra: uma possibilidade para a educação interdisciplinar?. Revista Novas Tecnologias na Educação, v. 9, n. 1, jul, 2011.

MENEZES, Daniel Brandão. O uso de dobraduras como recurso para o ensino da geometria plana: História, Teorema e Problemas. Fortaleza: UFC, 2014, 67 p. Programa de Pós-Graduação em Matemática em Rede Nacional do Departamento de Matemática, Universidade Federal do Ceará, 2014. Disponível em: http://www.teses.ufc.br/tde_busca/arquivo.php?codArquivo=11674. Acesso em: 29/10/2018.

NOTARE, Márcia; BASSO, Marcus. Argumentação e Prova Matemática com Geometria Dinâmica. Revista Novas Tecnologias na Educação, v. 16, n. 1, jul, 2018.

STAHL, Gerry. Translating Euclid. USA, 2013. Disponível em: http://gerrystahl.net/elibrary/euclid/euclid.pdf. Acesso: em 10/05/2020. 